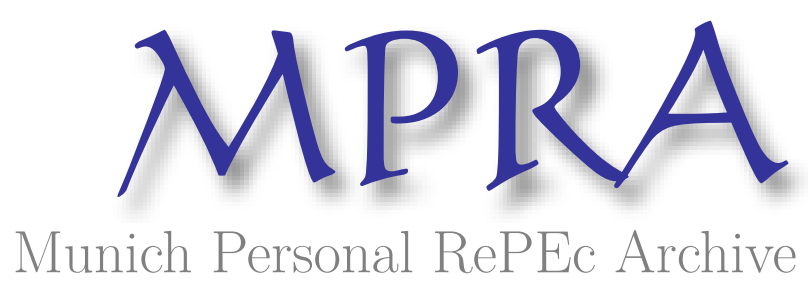

\title{
Unions, innovation and cross-country wage inequality
}

Chu, Angus C. and Cozzi, Guido and Furukawa, Yuichi

University of Liverpool, University of St. Gallen, Chukyo University

September 2014

Online at https://mpra.ub.uni-muenchen.de/67358/

MPRA Paper No. 67358, posted 21 Oct 2015 13:20 UTC 


\title{
Unions, Innovation and Cross-Country Wage Inequality
}

\author{
Angus C. Chu, University of Liverpool \\ Guido Cozzi, University of St. Gallen Yuichi Furukawa, Chukyo University
}

October 2015

\begin{abstract}
This study explores the macroeconomic effects of labor unions in a two-country R\&Dbased growth model in which the market size of each country determines the incentives for innovation. We find that an increase in the bargaining power of a wage-oriented union leads to a decrease in employment in the domestic economy. This result has two important implications on innovation. First, it reduces the rates of innovation and economic growth. Second, it causes innovation to be directed to the foreign economy, which in turn causes a negative effect on domestic wages relative to foreign wages in the long run. We also derive welfare implications and calibrate our model to data in the US and the UK to quantify the effects of labor unions on social welfare and wage inequality across countries. Our calibrated model is able to explain about half of the decrease in relative wage between the US and the UK from 1980 to 2007. Furthermore, the decrease in unions' bargaining power leads to quantitatively significant welfare gains in the two countries.
\end{abstract}

JEL classification: O30, O43, E24, J51

Keywords: economic growth, R\&D, labor unions, wage inequality

Chu: angusccc@gmail.com. University of Liverpool Management School, University of Liverpool, UK.

Cozzi: guido.cozzi@unisg.ch. Department of Economics, University of St. Gallen, Switzerland.

Furukawa: you.furukawa@gmail.com. School of Economics, Chukyo University, Nagoya, Japan. 


\section{Introduction}

This study explores the macroeconomic effects of labor unions in an open-economy R\&D-based growth model. We consider a two-country model in which a labor union bargains with employers over wages and employment in each country and the market size of each country determines the incentives for innovation. Within this growth-theoretic framework, we find that an increase in the bargaining power of a wage-oriented union leads to a decrease in employment in the domestic economy. In contrast, an increase in the bargaining power of an employment-oriented union leads to an increase in employment. Empirical studies ${ }^{1}$ often find that increasing the degree of unionization has a negative effect on employment, which is consistent with our result under a wageoriented union. This result has two important implications on innovation. First, by decreasing employment, an increase in the bargaining power of a wage-oriented union reduces the rates of innovation and economic growth. This theoretical implication is consistent with empirical studies that find negative effects of unions on innovation and growth. ${ }^{2}$ Second, by decreasing employment and the market size of the domestic economy, an increase in the bargaining power of a wageoriented union causes innovation to be directed to the foreign economy, which in turn causes a negative long-run effect on domestic wages relative to foreign wages. In the long run, this negative effect on relative wage income across countries would dominate the positive effect of labor unions on wages if the elasticity of substitution between domestic and foreign goods is sufficiently large. We also derive welfare implications and discuss them in the main text.

To provide an illustrative numerical analysis, we calibrate our model to data in the US and the UK. We consider the cross-country effects of labor unions between the US and the UK for the following reasons. We consider the US because it is the largest economy in the world. The largest trading partner of the US is the European Union. Within the European Union, the UK has a similar set of institutions that govern unionization and collective bargaining as the US. As Card et al. (2004) point out, "[a]s with other aspects of the economy, collective bargaining institutions in these countries are broadly similar... Thus it is possible to compare the structure of wages for workers whose wages are set by union contracts... A similar task is far more difficult in other countries including the major European countries...".

Figure 1a plots the HP-filter trends of labor income share of GDP from 1980 to 2007 in the US and the UK. ${ }^{3}$ This figure shows a well-documented stylized fact that the labor share of income has gradually declined since the early 1980's. Figure 1b plots the HP-filter trends of unemployment rates in the two countries. ${ }^{4}$ This figure shows that unemployment has also gradually declined in these two countries until 2007. ${ }^{5}$ We calibrate our model to compute the degree of unions' wage orientation and the decrease in workers' bargaining power that enable the model to replicate this simultaneous decrease in labor income share and unemployment in the two countries. We find that the degree of unions' wage orientation must be stronger in the UK than in the US in order

\footnotetext{
${ }^{1}$ See for example Montgomery (1989), Blanchflower et al. (1991), Nickell and Layard (1999) and Krol and Svorny (2007).

${ }^{2}$ See for example Connolly et al. (1986), Hirsch and Link (1987), Acs and Audretsch (1988), Carmeci and Mauro (2003) and Bradley et al. (2015). In contrast, Schnabel and Wagner (1994) and Addison et al. (2001) find positive effects of unions on innovation and growth in Germany, which would be consistent with our results under an employment-oriented union.

${ }^{3}$ Data source: OECD Annual Indicators on Unit Labour Costs.

${ }^{4}$ Data source: US Bureau of Labor Statistics, and UK Office for National Statistics.

${ }^{5}$ We do not consider data after 2007 because of the financial crisis.
} 
for the calibrated economies to match the data. We also explore the quantitative implications on social welfare and wage inequality across the two countries. Our calibrated model is able to explain about half of the decrease in relative wage between the US and the UK from 1980 to 2007. Furthermore, we find that both countries gain from the decrease in unions' bargaining power, but the welfare improvement in the UK is greater than that in the US due to changes in relative wage income. Specifically, the welfare gains are equivalent to a permanent increase in consumption of $5.2 \%$ in the US and $8.1 \%$ in the UK.

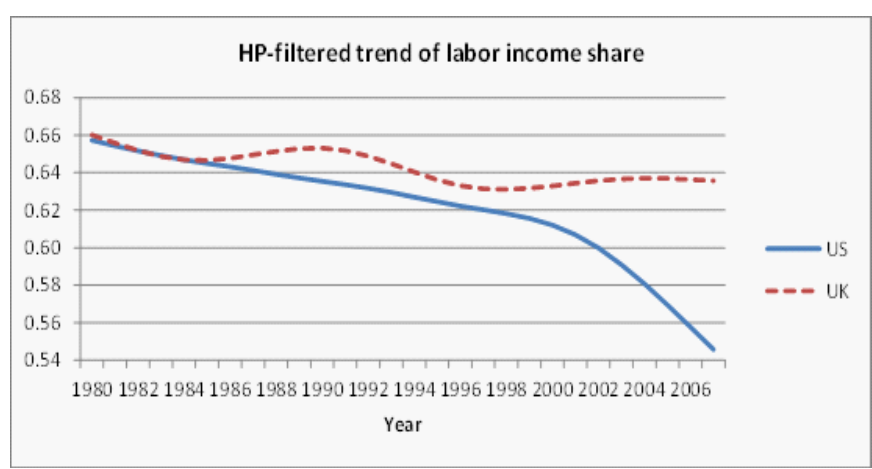

Figure 1a

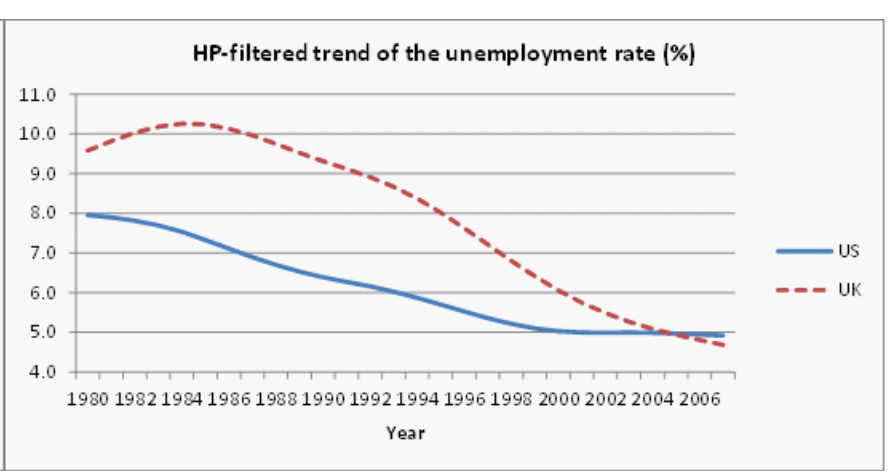

Figure $1 b$

This study relates to the literature on labor unions. Early studies in this literature focus on the formulation of labor unions' objective function; see for example Oswald (1985) for a survey. We follow a common approach in the literature to specify a Stone-Geary union objective function over wages and employment. Pemberton (1988) provides a microeconomic foundation for this union objective function as "the outcome of an internal bargain between the leadership and membership" in a managerial union. Our study relates most closely to a recent branch of this literature that explores the effects of labor unions on innovation and economic growth. Palokangas (1996) is the seminal study in this branch of the literature. Subsequent studies, such as Palokangas (2000, 2004, 2005), Boone (2000) and Ji et al. (2015), also analyze the effects of labor unions in R\&D-based growth models. ${ }^{6}$ Palokangas $(1996,2000,2004,2005)$ finds that increasing the bargaining power of labor union serves to increase economic growth, whereas Boone (2000) finds that labor union dampens economic growth. Ji et al. (2015) find that labor union has both a negative growth effect via unemployment and a positive growth effect via endogenous market structure, and these two effects exactly offset each other leaving an overall neutral effect on growth. Our theoretical model is able to replicate (via an alternative mechanism) the above results that increasing the bargaining power of labor unions can have a positive effect on growth and innovation (under an employment-oriented union), a negative effect on growth and innovation (under a wage-oriented union) and a neutral effect on growth and innovation (when the union is neither wage nor employment oriented). ${ }^{7}$ In addition to analyzing the effects of labor unions on the level of innovation

\footnotetext{
${ }^{6}$ See also Peretto (2011) who explores the interaction between the market power of unions in the labor market and the market power of firms in the product market.

${ }^{7}$ Chang et al. (2007) also find that unions' wage orientation determines the effects of their bargaining power on economic growth, but they consider an AK-type growth model in which economic growth is driven by capital
} 
within an economy as is common in the literature, ${ }^{8}$ our study also explores the effects of labor unions on the direction of innovation and wage inequality across countries, complementing the abovementioned studies in the literature.

An interesting study by Acemoglu et al. (2001) considers the relationship between labor unions and the direction of innovation across sectors within a country. They analyze the endogenous formation of labor unions but take innovation as an exogenous change in productivity parameters, whereas our study provides a complementary analysis by taking the existence of labor unions as given and exploring their effects on the direction of innovation across countries, instead of sectors. This open-economy analysis allows us to explore the cross-country welfare effects of unions and also how the relative market size of countries affects the allocation of $R \& D$ resources across countries. In a standard model of directed technical change, ${ }^{9}$ the market size of a sector is measured by the amount of labor in the sector. Similarly, the market size of a country is measured by the level of employment in the country. The presence of labor unions affects employment in the two countries, which in turn affects the amount of profits generated by intermediate goods. Consequently, labor unions have an effect on the value of inventions and hence the allocation of $R \& D$ resources across countries.

The rest of this study is organized as follows. Section 2 presents the model. Section 3 provides analytical results. Section 4 conducts a quantitative analysis. The final section concludes. Proofs are relegated to the appendix.

\section{The model}

In this section, we consider an open-economy version of the R\&D-based growth model originated from the seminal study by Romer (1990). ${ }^{10}$ In the model, there are two countries: Home and Foreign. Final goods are produced by combining intermediate goods from the two countries via a standard CES Armington aggregator. Intermediate goods in each country are produced using domestic labor and differentiated monopolistic inputs. The number of varieties of these differentiated inputs increases over time as a result of R\&D. In each country, there is a representative labor union that bargains with a representative federation of employers to determine wage and employment, which in turn determines the market size of each country. As a result, changes in employment in a country potentially affect the direction of innovation across countries.

accumulation. Our study complements their interesting analysis by exploring the effects of labor unions in an open-economy R\&D-based growth model.

${ }^{8}$ An exception is Palokangas (2005), who explores an open economy with unions and international R\&D spillovers; however, he does not consider the direction of innovation and wage inequality across countries.

${ }^{9}$ See for example Acemoglu $(1998,2002)$. Other influential studies on directed technical change include Acemoglu (2003), Acemoglu and Zilibotti (2001), Gancia and Bonfiglioli (2008) and Gancia and Zilibotti (2009).

${ }^{10}$ See also Aghion and Howitt (1992), Grossman and Helpman (1991) and Segerstrom et al. (1990) for other seminal studies on the R\&D-based growth model and Gancia and Zilibotti (2005) for a survey of this literature. 


\section{$2.1 \quad$ Household}

In the Home country $h$, there is a representative household, which has the following lifetime utility function:

$$
U^{h}=\int_{0}^{\infty} e^{-\rho t} \ln c_{t}^{h} d t,
$$

where $c_{t}^{h}$ denotes consumption of final goods at time $t$, and $\rho>0$ is the subjective discount rate. The household maximizes utility subject to the following asset-accumulation equation: ${ }^{11}$

$$
\dot{a}_{t}^{h}=r_{t} a_{t}^{h}+w_{t}^{h} l_{t}^{h}+b_{t}^{h}\left(L^{h}-l_{t}^{h}\right)-\tau_{t}^{h}-c_{t}^{h} .
$$

$a_{t}^{h}$ is the amount of financial assets (i.e., the equity shares of domestic and/or foreign firms that generate monopolistic profits) owned by the household in the Home country, and $r_{t}$ is the real interest rate. ${ }^{12} w_{t}^{h}$ is the wage rate in the Home country. $L^{h}$ is the inelastic supply of labor, and $l_{t}^{h}$ is employment. Therefore, $L^{h}-l_{t}^{h}$ is unemployment, and the unemployment rate is $u_{t}^{h} \equiv 1-l_{t}^{h} / L^{h} .{ }^{13}$ $b_{t}^{h}$ is unemployment benefit, and $\tau_{t}^{h}$ is a lump-sum tax levied by the government on the household. From standard dynamic optimization, the Euler equation is ${ }^{14}$

$$
\frac{\dot{c}_{t}^{h}}{c_{t}^{h}}=r_{t}-\rho .
$$

There are analogous conditions and variables with a superscript $f$ in the Foreign country.

\section{$2.2 \quad$ Final goods}

Final goods are homogeneous across countries, and their production is perfectly competitive. We also assume that they are freely traded across countries. ${ }^{15}$ Final goods are produced with the following CES Armington aggregator:

$$
Y_{t}=\left[\gamma\left(X_{t}^{h}\right)^{(\varepsilon-1) / \varepsilon}+(1-\gamma)\left(X_{t}^{f}\right)^{(\varepsilon-1) / \varepsilon}\right]^{\varepsilon /(\varepsilon-1)}
$$

\footnotetext{
${ }^{11}$ We also impose the usual no-Ponzi-game condition that requires the household's lifetime budget constraint to be satisfied.

${ }^{12} r_{t}$ is not indexed by a country superscript because we consider a global financial market. Our derivations are robust to any distribution of financial assets across the two countries. In other words, we do not impose any restriction on which country owns more (or even all) of the monopolistic firms and whether there is any foreign bond holding between the two countries. The distribution of financial assets across countries affects the relative level of consumption across countries, but not the steady-state equilibrium levels of other variables. The households' budget constraints ensure the balance of payments; see Appendix B for the derivations. One special case is that all domestic (foreign) firms are owned by the domestic (foreign) household and that there is zero foreign bond holding. Only when we examine welfare implications, we focus on this special case to pin down the levels of consumption in the two countries.

${ }^{13}$ In this simple model, unemployment is caused by the union. In the absence of the union, all labor $L^{h}$ will be employed by firms.

${ }^{14} \mathrm{Also}$, the transversality condition requires $r_{t}>\dot{a}_{t}^{h} / a_{t}^{h}$, which holds on the balanced growth path given the log utility function and $\rho>0$.

${ }^{15}$ As a result, we do not impose any restriction on the location of the production of final goods. Suppose all final goods are produced in the Foreign (Home) country. Then, the Home (Foreign) country would import final goods and export intermediate goods.
} 
where $X_{t}^{h}$ and $X_{t}^{f}$ are respectively intermediate goods produced in the Home and Foreign countries. The parameter $\varepsilon>1^{16}$ is the Armington elasticity of substitution between the two types of intermediate goods, and the parameter $\gamma \in(0,1)$ determines their relative importance. We choose final goods as the numeraire, and the standard price index of final goods is

$$
1=\left[\gamma^{\varepsilon}\left(P_{t}^{h}\right)^{1-\varepsilon}+(1-\gamma)^{\varepsilon}\left(P_{t}^{f}\right)^{1-\varepsilon}\right]^{1 /(1-\varepsilon)}
$$

where we have set the price of final goods to one. $P_{t}^{h}$ and $P_{t}^{f}$ are respectively the price of $X_{t}^{h}$ and $X_{t}^{f}$. The conditional demand functions for intermediate goods are

$$
\begin{gathered}
X_{t}^{h}=\left(\frac{\gamma}{P_{t}^{h}}\right)^{\varepsilon} Y_{t}, \\
X_{t}^{f}=\left(\frac{1-\gamma}{P_{t}^{f}}\right)^{\varepsilon} Y_{t} .
\end{gathered}
$$

\subsection{Intermediate goods and labor union}

There is a unit continuum of firms producing intermediate goods in each country. The production function of $X_{t}^{h}$ is given by

$$
X_{t}^{h}=\left(l_{t}^{h}\right)^{\alpha} \int_{0}^{N_{t}^{h}}\left[x_{t}^{h}(i)\right]^{\beta} d i,
$$

where $l_{t}^{h}$ is the employment of labor and $x_{t}^{h}(i)$ is differentiated input $i \in\left[0, N_{t}^{h}\right]$. We also impose the following parameter restrictions: $\alpha, \beta \in(0,1)$ and $\alpha+\beta<1$. Here we follow previous studies on unions and bargaining such as Palokangas (1996, 2005), Chang et al. (2007), Chang and Hung (2015) and Ji et al. (2015) to assume decreasing returns to scale, ${ }^{17}$ allowing the firms to have positive profit in order to facilitate the bargaining process between the employers' federation and the labor union. ${ }^{18}$ The profit function of the representative firm is

$$
\Pi_{t}^{h}=P_{t}^{h} X_{t}^{h}-w_{t}^{h} l_{t}^{h}-\int_{0}^{N_{t}^{h}} p_{t}^{h}(i) x_{t}^{h}(i) d i,
$$

where $p_{t}^{h}(i)$ is the price of $x_{t}^{h}(i)$. The firm chooses $x_{t}^{h}(i)$ to maximize $\Pi_{t}^{h}$. The conditional demand function for $x_{t}^{h}(i)$ is

$$
p_{t}^{h}(i)=\beta P_{t}^{h}\left(l_{t}^{h}\right)^{\alpha}\left[x_{t}^{h}(i)\right]^{\beta-1} .
$$

\footnotetext{
${ }^{16}$ McDaniel and Balistreri (2003) provide a survey of empirical estimates of this Armington elasticity of substitution. Although point estimates vary across studies, they are mostly larger than one.

${ }^{17}$ This assumption can be justified by the presence of a fixed factor input owned by the firms. For example, this fixed factor input may be the entrepreneurial talent of the firms' owners. Given that not everyone possesses this entrepreneurial talent, there is no free entry in this sector generating a monopolistic rent that is captured by the firms' owners.

${ }^{18}$ As $\alpha+\beta \rightarrow 1$, the bargaining power of the two parties would cease to have any influence on the equilibrium level of employment as we will show in (25) and (26).
} 
Departing from models without labor union, we follow previous studies to consider a representative labor union that bargains with a representative federation of employers to determine wage $w_{t}^{h}$ and employment $l_{t}^{h}$. For simplicity, we consider a closed shop union under which only union members are eligible for employment. As in Pemberton (1988) and Chang et al. (2007), we consider a managerial union whose objective is influenced by the union leaders' desire for a larger membership and the members' desire for a higher wage. Formally, the union's objective is given by a standard Stone-Geary function: ${ }^{19}$

$$
O_{t}^{h}=\left(w_{t}^{h}-b_{t}^{h}\right)^{\omega^{h}}\left(l_{t}^{h}\right)^{\lambda^{h}}
$$

The parameter $\omega^{h}>0$ measures the weight that the union places on workers' incremental wage income from employment (i.e., wage minus unemployment benefit). The parameter $\lambda^{h}>0$ measures the weight that the union places on membership. For simplicity, we normalize $\lambda^{h}$ to unity and use $\omega^{h}$ to measure the weight that the union places on wage relative to membership; i.e., we focus on $\lambda^{h}=1$ for the rest of the analysis. ${ }^{20}$ When $\omega^{h}>1\left(\omega^{h}<1\right)$, we refer to the union as being wage-oriented (employment-oriented).

The employers' federation and the labor union bargain over $w_{t}^{h}$ and $l_{t}^{h}{ }^{21}$ The generalized Nash bargaining function is

$$
\max _{w_{t}^{h}, l_{t}^{h}} B_{t}^{h}=\left(O_{t}^{h}\right)^{\theta^{h}}\left(\Pi_{t}^{h}\right)^{1-\theta^{h}}
$$

where the parameter $\theta^{h} \in(0,1)$ measures the bargaining power of the labor union relative to the employers. The bargaining solutions are

$$
\begin{gathered}
\frac{\partial B_{t}^{h}}{\partial w_{t}^{h}}=0 \Leftrightarrow \frac{\left(w_{t}^{h}-b_{t}^{h}\right) l_{t}^{h}}{\Pi_{t}^{h}}=\frac{\omega^{h} \theta^{h}}{1-\theta^{h}}, \\
\frac{\partial B_{t}^{h}}{\partial l_{t}^{h}}=0 \Leftrightarrow \frac{w_{t}^{h} l_{t}^{h}-\alpha P_{t}^{h} X_{t}^{h}}{\Pi_{t}^{h}}=\frac{\theta^{h}}{1-\theta^{h}} .
\end{gathered}
$$

There are analogous conditions for $w_{t}^{f}$ and $l_{t}^{f}$ in the Foreign country.

\subsection{Differentiated inputs}

In each country, there is a continuum of industries producing differentiated inputs $i \in\left[0, N_{t}^{h}\right]$. Each differentiated input $i$ is produced by a monopolist who owns a patent on the production technology. For simplicity, we follow Acemoglu (2002) to assume that these differentiated inputs are produced using final goods. In particular, one unit of final goods produces one unit of differentiated input; therefore, the cost of producing $x_{t}^{h}(i)$ units of differentiated input is $x_{t}^{h}(i)$ units of final goods,

\footnotetext{
${ }^{19}$ Here we follow Chang et al. (2007) to assume that the union objective function depends only on current wages and employment. This simplifying assumption allows for a tractable analysis of transition dynamics.

${ }^{20}$ Our results are robust to $\lambda^{h}>0$ (derivations available upon request), but some of the expressions become more complicated in this case.

${ }^{21}$ In this study, we focus on efficient bargaining. In the case of right-to-manage bargaining (under which the union and employers bargain over wages only), equilibrium employment and economic growth are unambiguously decreasing in the union's bargaining power, contradicting evidence from some empirical studies (discussed in footnote 2). Derivations are available upon request.
} 
which have been chosen as the numeraire. The profit function of the monopolist in industry $i$ is given by

$$
\pi_{t}^{h}(i)=p_{t}^{h}(i) x_{t}^{h}(i)-x_{t}^{h}(i)=\beta P_{t}^{h}\left(l_{t}^{h}\right)^{\alpha}\left[x_{t}^{h}(i)\right]^{\beta}-x_{t}^{h}(i),
$$

where the second equality uses (10). Differentiating (15) with respect to $x_{t}^{h}(i)$, we find the familiar profit-maximizing price of $x_{t}^{h}(i)$ given by $p_{t}^{h}(i)=1 / \beta$. Substituting $p_{t}^{h}(i)=1 / \beta$ into (10) and (15) yields

$$
\begin{gathered}
x_{t}^{h}(i)=\left[\beta^{2} P_{t}^{h}\left(l_{t}^{h}\right)^{\alpha}\right]^{1 /(1-\beta)} \equiv x_{t}^{h}, \\
\pi_{t}^{h}(i)=\left(\frac{1-\beta}{\beta}\right) x_{t}^{h}(i)=\left(\frac{1-\beta}{\beta}\right)\left[\beta^{2} P_{t}^{h}\left(l_{t}^{h}\right)^{\alpha}\right]^{1 /(1-\beta)} \equiv \pi_{t}^{h} .
\end{gathered}
$$

There are analogous conditions for $x_{t}^{f}$ and $\pi_{t}^{f}$ in the Foreign country.

\section{$2.5 \quad R \& D$}

The invention of a new variety of differentiated inputs for the Home country requires $\mu^{h}$ units of final goods. Similarly, the invention of a new variety of differentiated inputs for the Foreign country requires $\mu^{f}$ units of final goods. In other words, we consider the lab-equipment R\&D specification as in Rivera-Batiz and Romer (1991). ${ }^{22}$ In particular, the innovation process of new varieties for the Home country is given by

$$
\dot{N}_{t}^{h}=R_{t}^{h} / \mu^{h}
$$

where $R_{t}^{h}$ is the amount of final goods devoted to creating new varieties for the Home country. ${ }^{23}$ Suppose we denote $v_{t}^{h}$ as the value of an invention in the Home country. Free entry in the R\&D sector implies

$$
\left(v_{t}^{h}-\mu^{h}\right) \dot{N}_{t}^{h}=0 .
$$

The familiar Bellman equation is

$$
r_{t}=\frac{\pi_{t}^{h}+\dot{v}_{t}^{h}}{v_{t}^{h}}
$$

Intuitively, the Bellman equation equates the interest rate to the asset return per unit of asset, where the asset return is the monopolistic profit $\pi_{t}^{h}$ plus any potential capital gain $\dot{v}_{t}^{h}$. There are analogous conditions for $v_{t}^{f}$ in the Foreign country.

\footnotetext{
${ }^{22}$ In Section 2.8, we will discuss the implications under an alternative R\&D specification.

${ }^{23}$ It is useful to note that we do not impose any restriction on the location of R\&D. An inventor in either country may create a new variety for the Home country with productivity $1 / \mu^{h}$ or for the Foreign country with productivity $1 / \mu^{f}$.
} 


\subsection{Government}

In each country, there is a government that determines unemployment benefit and levies a lumpsum tax on the household to balance the fiscal budget. The balanced-budget condition in the Home country is

$$
\tau_{t}^{h}=b_{t}^{h}\left(L^{h}-l_{t}^{h}\right) .
$$

To be consistent with balanced growth, we assume that unemployment benefit $b_{t}^{h}$ is proportional to the value of domestic output $P_{t}^{h} X_{t}^{h}$; i.e., $b_{t}^{h}=\bar{b}^{h} P_{t}^{h} X_{t}^{h}$, where $\bar{b}^{h}>0$ is a policy parameter. There are analogous conditions for $\tau_{t}^{f}$ and $b_{t}^{f}$ in the Foreign country.

\subsection{Decentralized equilibrium}

An equilibrium is a time path of allocations $\left\{c_{t}^{h}, c_{t}^{f}, Y_{t}, X_{t}^{h}, X_{t}^{f}, x_{t}^{h}(i), x_{t}^{f}(i), l_{t}^{h}, l_{t}^{f}, R_{t}^{h}, R_{t}^{f}\right\}$, prices $\left\{r_{t}, w_{t}^{h}, w_{t}^{f}, P_{t}^{h}, P_{t}^{f}, p_{t}^{h}(i), p_{t}^{f}(i), v_{t}^{h}, v_{t}^{f}\right\}$ and fiscal policies $\left\{\tau_{t}^{h}, \tau_{t}^{f}, b_{t}^{h}, b_{t}^{f}\right\}$ such that the following conditions hold at each instance of time:

- the representative household in the Home country chooses $\left\{c_{t}^{h}\right\}$ to maximize utility taking $\left\{r_{t}, w_{t}^{h}, b_{t}^{h}, \tau_{t}^{h}\right\}$ as given;

- the representative household in the Foreign country chooses $\left\{c_{t}^{f}\right\}$ to maximize utility taking $\left\{r_{t}, w_{t}^{f}, b_{t}^{f}, \tau_{t}^{f}\right\}$ as given;

- perfectly competitive final-goods firms produce $\left\{Y_{t}\right\}$ to maximize profit taking prices $\left\{P_{t}^{h}, P_{t}^{f}\right\}$ as given;

- intermediate-goods firms in the Home country produce $\left\{X_{t}^{h}\right\}$ to maximize profit taking prices $\left\{P_{t}^{h}, p_{t}^{h}(i)\right\}$ as given;

- intermediate-goods firms in the Foreign country produce $\left\{X_{t}^{f}\right\}$ to maximize profit taking prices $\left\{P_{t}^{f}, p_{t}^{f}(i)\right\}$ as given;

- in the Home country, a representative federation representing intermediate-goods firms bargains with a representative labor union to determine $\left\{w_{t}^{h}, l_{t}^{h}\right\}$;

- in the Foreign country, a representative federation representing intermediate-goods firms bargains with a representative labor union to determine $\left\{w_{t}^{f}, l_{t}^{f}\right\}$;

- monopolistic firms in the Home country produce differentiated inputs $\left\{x_{t}^{h}(i)\right\}$ and set $\left\{p_{t}^{h}(i)\right\}$ to maximize profit;

- monopolistic firms in the Foreign country produce differentiated inputs $\left\{x_{t}^{f}(i)\right\}$ and set $\left\{p_{t}^{f}(i)\right\}$ to maximize profit;

- R\&D firms choose $\left\{R_{t}^{h}, R_{t}^{f}\right\}$ to maximize profit taking $\left\{r_{t}, v_{t}^{h}, v_{t}^{f}\right\}$ as given;

- the market-clearing condition for final goods holds such that $Y_{t}=R_{t}^{h}+R_{t}^{f}+N_{t}^{h} x_{t}^{h}+N_{t}^{f} x_{t}^{f}+$ $c_{t}^{h}+c_{t}^{f}$ 
- the government in the Home country balances its fiscal budget given by $\tau_{t}^{h}=b_{t}^{h}\left(L^{h}-l_{t}^{h}\right)$;

- the government in the Foreign country balances its fiscal budget given by $\tau_{t}^{f}=b_{t}^{f}\left(L^{f}-l_{t}^{f}\right)$.

\subsubsection{Equilibrium employment}

Here we first derive the equilibrium levels of employment in the two countries. Substituting (8) and (10) into (9) yields the profit function of intermediate goods in the Home country given by

$$
\Pi_{t}^{h}=(1-\beta) P_{t}^{h}\left(l_{t}^{h}\right)^{\alpha} \int_{0}^{N_{t}^{h}}\left[x_{t}^{h}(i)\right]^{\beta} d i-w_{t}^{h} l_{t}^{h}=(1-\beta) P_{t}^{h} X_{t}^{h}-w_{t}^{h} l_{t}^{h} .
$$

Substituting (22) into the bargaining solution in (14) yields

$$
w_{t}^{h} l_{t}^{h}=\left[\alpha+\theta^{h}(1-\alpha-\beta)\right] P_{t}^{h}\left(l_{t}^{h}\right)^{\alpha} \int_{0}^{N_{t}^{h}}\left[x_{t}^{h}(i)\right]^{\beta} d i=\left[\alpha+\theta^{h}(1-\alpha-\beta)\right] P_{t}^{h} X_{t}^{h},
$$

where labor income share $w_{t}^{h} l_{t}^{h} / P_{t}^{h} X_{t}^{h}=\alpha+\theta^{h}(1-\alpha-\beta)$ is increasing in the union's bargaining power $\theta^{h}$. Then, substituting (23) into (22) yields

$$
\Pi_{t}^{h}=\left(1-\theta^{h}\right)(1-\alpha-\beta) P_{t}^{h}\left(l_{t}^{h}\right)^{\alpha} \int_{0}^{N_{t}^{h}}\left[x_{t}^{h}(i)\right]^{\beta} d i=\left(1-\theta^{h}\right)(1-\alpha-\beta) P_{t}^{h} X_{t}^{h} .
$$

Substituting (23), (24) and $b_{t}^{h}=\bar{b}^{h} P_{t}^{h} X_{t}^{h}$ into the bargaining solution in (13) yields the equilibrium level of employment in the Home country given by

$$
l_{t}^{h}=\frac{\alpha+\left(1-\omega^{h}\right) \theta^{h}(1-\alpha-\beta)}{\bar{b}^{h}} \equiv l^{h},
$$

where employment $l^{h}$ is decreasing in the union's wage orientation $\omega^{h}$ and is ambiguous with respect to its bargaining power $\theta^{h}$ depending on the value of $\omega^{h}$. We impose parameter restrictions to ensure $l_{t}^{h} \in\left(0, L^{h}\right)$. By analogous inference, the equilibrium level of employment in the Foreign country is given by

$$
l_{t}^{f}=\frac{\alpha+\left(1-\omega^{f}\right) \theta^{f}(1-\alpha-\beta)}{\bar{b}^{f}} \equiv l^{f} .
$$

We also impose parameter restrictions to ensure $l_{t}^{f} \in\left(0, L^{f}\right)$. Equations (25) and (26) give the equilibrium levels of employment $\left\{l^{h}, l^{f}\right\}$ regardless of whether the economy is on or off the balanced growth path. 


\subsubsection{Relative wage and relative technologies across countries}

We now derive the relative wage across countries. Combining (6) and (7) yields the relative demand function for intermediate goods given by

$$
\frac{P_{t}^{h}}{P_{t}^{f}}=\frac{\gamma}{1-\gamma}\left(\frac{X_{t}^{h}}{X_{t}^{f}}\right)^{-1 / \varepsilon} .
$$

Substituting (16) into (8) yields the production of intermediate goods $X_{t}^{h}$ given by

$$
X_{t}^{h}=\left(l^{h}\right)^{\alpha /(1-\beta)}\left(\beta^{2} P_{t}^{h}\right)^{\beta /(1-\beta)} N_{t}^{h} .
$$

Substituting (28) and the analogous condition for $X_{t}^{f}$ into (27) yields

$$
\frac{P_{t}^{h}}{P_{t}^{f}}=\left(\frac{\gamma}{1-\gamma}\right)^{\frac{(1-\beta) \varepsilon}{\beta+(1-\beta) \varepsilon}}\left(\frac{l^{h}}{l^{f}}\right)^{-\frac{\alpha}{\beta+(1-\beta) \varepsilon}}\left(\frac{N_{t}^{h}}{N_{t}^{f}}\right)^{-\frac{(1-\beta)}{\beta+(1-\beta) \varepsilon}},
$$

which determines the relative price of $X_{t}^{h}$ and $X_{t}^{f}$. Substituting (16) into (23) yields the equilibrium wage rate in the Home country given by

$$
w_{t}^{h}=\beta^{2 \beta /(1-\beta)}\left[\alpha+\theta^{h}(1-\alpha-\beta)\right]\left(P_{t}^{h}\right)^{1 /(1-\beta)}\left(l^{h}\right)^{-\frac{1-\alpha-\beta}{1-\beta}} N_{t}^{h} .
$$

Combining (30) and the analogous expression for $w_{t}^{f}$ yields an expression for the relative wage across countries. If we substitute the relative price in (29) into this expression, we would obtain the equilibrium relative wage given by

$$
\frac{w_{t}^{h}}{w_{t}^{f}}=\frac{\alpha+\theta^{h}(1-\alpha-\beta)}{\alpha+\theta^{f}(1-\alpha-\beta)}\left(\frac{\gamma}{1-\gamma}\right)^{\frac{\varepsilon}{\beta+(1-\beta) \varepsilon}}\left(\frac{l^{h}}{l^{f}}\right)^{-\frac{\alpha+\beta+(1-\alpha-\beta) \varepsilon}{\beta+(1-\beta) \varepsilon}}\left(\frac{N_{t}^{h}}{N_{t}^{f}}\right)^{\frac{(1-\beta)(\varepsilon-1)}{\beta+(1-\beta) \varepsilon}}
$$

which is decreasing in relative employment $l^{h} / l^{f}$ but increasing in relative technology $N_{t}^{h} / N_{t}^{f}$. Equation (31) gives the equilibrium relative wage regardless of whether the economy is on or off the balanced growth path. Proposition 1 characterizes the dynamic property of $N_{t}^{h} / N_{t}^{f}$.

Proposition 1 There is a unique and globally stable steady-state equilibrium value of $N_{t}^{h} / N_{t}^{f}$. When $N_{t}^{h} / N_{t}^{f}$ is below (above) this steady-state value, $N_{t}^{h} / N_{t}^{f}$ increases (decreases) until $N_{t}^{h} / N_{t}^{f}$ reaches the steady state, at which point $N_{t}^{h}$ and $N_{t}^{f}$ grow at the same rate.

Proof. See Appendix A.

Next we derive the steady-state equilibrium value of $N_{t}^{h} / N_{t}^{f}$. In the long run, innovation takes place in both countries; therefore, we have $v_{t}^{h}=\mu^{h}$, which in turn implies that $\dot{v}_{t}^{h}=0$. Substituting $\dot{v}_{t}^{h}=0$ into (20), we obtain the equilibrium value of an invention in the Home country given by

$$
v^{h}=\frac{\pi^{h}}{r}=\left(\frac{1-\beta}{\beta}\right) \frac{\left[\beta^{2} P^{h}\left(l^{h}\right)^{\alpha}\right]^{1 /(1-\beta)}}{r},
$$


where the second equality follows from (17). Combining (32) with the analogous expression for $v^{f}$, we obtain the relative value of inventions across countries given by

$$
\frac{v^{h}}{v^{f}}=\left(\frac{P^{h}}{P^{f}}\right)^{1 /(1-\beta)}\left(\frac{l^{h}}{l^{f}}\right)^{\alpha /(1-\beta)}=\frac{\mu^{h}}{\mu^{f}}
$$

where the second equality follows from $v^{h}=\mu^{h}$ and $v^{f}=\mu^{f}$. Combining (29) and (33) yields the steady-state equilibrium value of $N_{t}^{h} / N_{t}^{f}$ given by

$$
\frac{N_{t}^{h}}{N_{t}^{f}}=\left(\frac{\mu^{f}}{\mu^{h}}\right)^{\beta+(1-\beta) \varepsilon}\left(\frac{\gamma}{1-\gamma}\right)^{\varepsilon}\left(\frac{l^{h}}{l^{f}}\right)^{\alpha(\varepsilon-1)},
$$

which is increasing in relative employment $l^{h} / l^{f}$ capturing the market-size effect on the direction of innovation across countries. Intuitively, a higher level of employment in the Home country increases both the amount of profits generated by intermediate goods and the value of inventions in the country. As a result, more inventions are created for this country. Lemma 1 summarizes this result on a positive relationship between the direction of innovation $N_{t}^{h} / N_{t}^{f}$ and the relative market size $l^{h} / l^{f} \cdot{ }^{24}$

Lemma 1 The steady-state value of $N_{t}^{h} / N_{t}^{f}$ is increasing in relative employment level $l^{h} / l^{f}$.

Proof. Use (34) and recall that $\varepsilon>1$.

Finally, we substitute (34) into (31) to derive the steady-state equilibrium relative wage.

$$
\frac{w_{t}^{h}}{w_{t}^{f}}=\frac{\alpha+\theta^{h}(1-\alpha-\beta)}{\alpha+\theta^{f}(1-\alpha-\beta)}\left(\frac{\mu^{f}}{\mu^{h}}\right)^{(1-\beta)(\varepsilon-1)}\left(\frac{\gamma}{1-\gamma}\right)^{\varepsilon}\left(\frac{l^{h}}{l^{f}}\right)^{\alpha(\varepsilon-1)-1} .
$$

Equation (35) shows that the steady-state value of $w_{t}^{h} / w_{t}^{f}$ is increasing in relative employment $l^{h} / l^{f}$ if and only if the substitution elasticity $\varepsilon$ is greater than $(1+\alpha) / \alpha$.

\subsection{Economic growth and social welfare}

In Lemma 2, we derive the steady-state equilibrium growth rate, which is monotonically increasing in the equilibrium levels of employment $\left\{l^{h}, l^{f}\right\} .{ }^{25}$ The implied negative relationship between unemployment and growth is consistent with the empirical evidence in Gordon (1997) and Brauninger

\footnotetext{
${ }^{24}$ Although our model features the scale effect as we will show in the next section, this result would continue to hold in a scale-invariant semi-endogenous-growth version of the model. In other words, the direction of innovation across countries will continue to depend on the relative market size of the two countries because the market-size effect requires only the level of technology (but not the growth rate of technology) to depend on the size of the domestic market.

${ }^{25}$ This is known as the scale effect in the literature. In a scale-invariant semi-endogenous-growth version of the model, an increase in employment would still lead to a higher growth rate in the short run (i.e., before the economy reaches the new balanced growth path).
} 
and Pannenberg (2002), who find that higher unemployment reduces growth. Therefore, whenever labor unions decrease employment, they also decrease economic growth. ${ }^{26}$

Lemma 2 The steady-state equilibrium growth rate of consumption is given by

$$
g=(1-\beta) \beta^{(1+\beta) /(1-\beta)}\left[\gamma^{\varepsilon} \frac{\left(l^{h}\right)^{\alpha(\varepsilon-1)}}{\left(\mu^{h}\right)^{(1-\beta)(\varepsilon-1)}}+(1-\gamma)^{\varepsilon} \frac{\left(l^{f}\right)^{\alpha(\varepsilon-1)}}{\left(\mu^{f}\right)^{(1-\beta)(\varepsilon-1)}}\right]^{\frac{1}{(1-\beta)(\varepsilon-1)}}-\rho .
$$

Proof. See Appendix A.

Using (1), we can express the representative household's lifetime welfare on the balanced growth path as

$$
U^{j}=\frac{1}{\rho}\left(\ln c_{0}^{j}+\frac{g}{\rho}\right)
$$

where $j \in\{h, f\}$ and we have defined $t=0$ as the time when the economy reaches the balanced growth path. All the previous derivations are robust to the distribution of assets across countries; however, to derive the level of consumption in each country, we now need to make an additional assumption on the cross-country distribution of assets (i.e., the equity shares of monopolistic firms in the two countries). Following the standard treatment in the literature, ${ }^{27}$ we assume home bias in asset holding under which domestic (foreign) firms are owned by the domestic (foreign) household. Furthermore, we assume zero foreign bond holding. Under these assumptions, we derive the following expression for $\ln c_{0}^{j}$ and $U^{j}$ in Lemma 3.

Lemma 3 Under home bias in asset holding, the steady-state welfare function is given by

$$
U^{j}=\frac{1}{\rho}\left\{\ln N_{0}^{j}+\ln \left[\frac{\mu^{j}}{\beta}[\rho(1+\beta)+g]\right]+\frac{g}{\rho}\right\} .
$$

Proof. See Appendix A.

Equation (38) shows that welfare $U^{j}$ is increasing in the equilibrium growth rate $g$, which is given by (36), and in the balanced-growth level of technology $N_{0}^{j}$, which is determined by (34). In this model, when the economy is on a transition path, new varieties are created only for one country until the economy reaches the new balanced growth path along which $N_{t}^{h}$ and $N_{t}^{f}$ grow at the same rate. In other words, whenever the steady-state value of $N_{t}^{h} / N_{t}^{f}$ increases (decreases), it must be the case that $\dot{N}_{t}^{h}>0$ and $\dot{N}_{t}^{f}=0\left(\dot{N}_{t}^{h}=0\right.$ and $\left.\dot{N}_{t}^{f}>0\right)$ during transition.

\footnotetext{
${ }^{26}$ If we consider an alternative innovation process in which labor is the factor input for $\mathrm{R} \& \mathrm{D}$, then the relationship between employment and economic growth could be different. For example, decreasing employment in the production sector may lead to an increase in R\&D employment and growth. Therefore, the lab-equipment innovation process in this study seems to be more consistent with empirical evidence on employment and growth in e.g., Gordon (1997) and Brauninger and Pannenberg (2002). Furthermore, although the lab-equipment innovation process ignores intertemporal knowledge spillovers on $\mathrm{R} \& \mathrm{D}$, the expanding varieties of intermediate goods improve labor productivity and increase the wage rate of labor as shown in (30).

${ }^{27}$ See for example Dinopoulos and Segerstrom (2010).
} 


\section{Macroeconomic effects of labor unions}

In this section, we explore the macroeconomic implications of labor unions. In particular, we are interested in the effects of a labor union becoming more wage oriented (i.e., $\omega^{h}$ increases) and having more bargaining power relative to employers (i.e., $\theta^{h}$ increases). In Section 3.1, we analyze the effects of increasing $\omega^{h} \cdot{ }^{28}$ In Section 3.2, we analyze the effects of increasing $\theta^{h}$.

\subsection{Wage orientation of labor unions}

Equation (25) shows that an increase in the union's wage orientation $\omega^{h}$ leads to a decrease in employment $l^{h}$ in the Home country. Intuitively, as the union in the Home country becomes more wage oriented, it demands a higher wage and depresses labor demand. Given that employment $l^{f}$ in the Foreign country is independent of $\omega^{h}$, an increase in $\omega^{h}$ leads to a decrease in relative employment $l^{h} / l^{f}$, which in turn increases relative wage $w_{t}^{h} / w_{t}^{f}$ across countries in the short run (i.e., for a given $N_{t}^{h} / N_{t}^{f}$ ) as shown in (31). This short-run increase in relative wage is partly due to the direct effect of the decrease in relative employment and partly due to an indirect effect via the increase in relative price $P_{t}^{h} / P_{t}^{f}$ as shown in (29). In the long run, $N_{t}^{h} / N_{t}^{f}$ decreases to a lower steady-state value as shown in (34) because the decrease in relative employment $l^{h} / l^{f}$ changes the relative market size of the two countries and causes innovation to be directed towards the Foreign country. This negative market-size effect partly offsets and may even dominate the positive price effect on relative wage $w_{t}^{h} / w_{t}^{f}$. Equation (35) shows that the overall effect of $\omega^{h}$ on $w_{t}^{h} / w_{t}^{f}$ would be negative if and only if the substitution elasticity $\varepsilon$ is sufficiently large (i.e., $\varepsilon>(1+\alpha) / \alpha)$. From Lemma 2, we see that the decrease in employment also reduces economic growth in the long run. Furthermore, $N_{t}^{h} / N_{t}^{f}$ decreasing to a lower steady-state value implies $\dot{N}_{t}^{h}=0$ and $\dot{N}_{t}^{f}>0$ until the economy reaches the new balanced growth path. Therefore, the increase in $\omega^{h}$ also reduces steady-state welfare in the Home country due to the lower growth rate, but the welfare effect in the Foreign country is ambiguous due to the opposing effects of $g$ and $N_{0}^{f}$ on $U^{f}$ in (38). We summarize these results in Proposition 2. Figure 2 plots the transitional path of $w_{t}^{h} / w_{t}^{f}$ in response to a permanent increase in $\omega^{h}$ at time $t$.

Proposition 2 As the labor union becomes more wage oriented, employment in the domestic economy decreases. This decrease in employment increases the wage rate in the domestic economy relative to the foreign economy in the short run. In the long run, the decrease in employment in the domestic economy causes innovation to be directed to the foreign economy, which causes a negative effect on the relative wage. The overall effect on the relative wage in the long run is negative if and only if the substitution elasticity $\varepsilon$ is greater than a threshold given by $(1+\alpha) / \alpha$. Finally, the effects on the steady-state growth rate and domestic welfare are negative.

Proof. See Appendix A.

\footnotetext{
${ }^{28}$ The effects of increasing unemployment benefit $\bar{b}^{h}$ are the same as increasing $\omega^{h}$.
} 


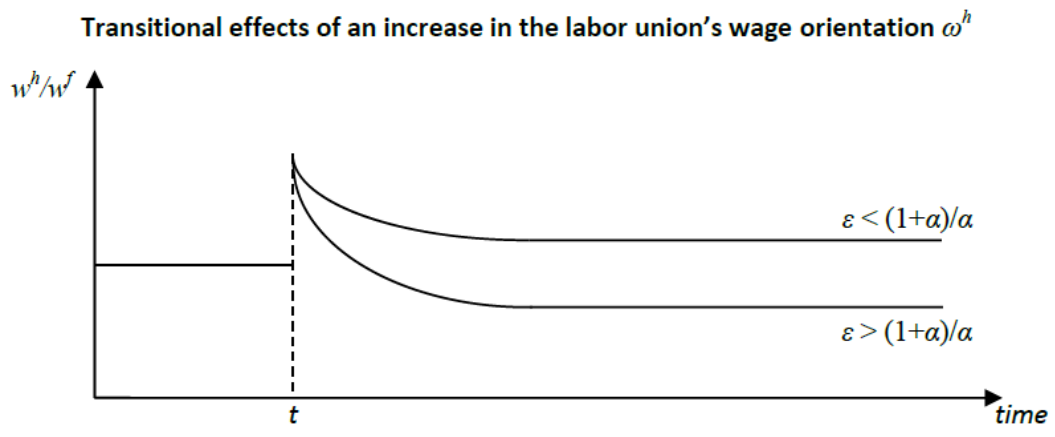

Figure 2

\subsection{Bargaining power of labor unions}

In this subsection, we first consider the case of a wage-oriented union (i.e., $\omega^{h}>1$ ). Equation (25) shows that an increase in the union's bargaining power $\theta^{h}$ leads to a decrease in employment $l^{h}$ if and only if the union is wage oriented. This decrease in employment $l^{h}$ has a positive effect on the wage rate in the Home country as shown in (30). Furthermore, an increase in the union's bargaining power increases the share of output that goes to wage income as shown in (23). These two positive effects on $w_{t}^{h}$ lead to an unambiguous increase in relative wage $w_{t}^{h} / w_{t}^{f}$ in the short run (i.e., for a given $N_{t}^{h} / N_{t}^{f}$ ) as shown in (31). However, in the long run, the decrease in employment $l^{h}$ exerts a negative market-size effect on $w_{t}^{h} / w_{t}^{f}$ by decreasing $N_{t}^{h} / N_{t}^{f}$. This negative market-size effect would dominate the abovementioned positive effects if the elasticity of substitution between Home and Foreign intermediate goods is sufficiently large; i.e., ${ }^{29}$

$$
\varepsilon>1+\frac{\omega^{h}}{\omega^{h}-1}\left[\frac{1}{\alpha+\theta^{h}(1-\alpha-\beta)}\right] \equiv \bar{\varepsilon} .
$$

The transitional path of $w_{t}^{h} / w_{t}^{f}$ in response to an increase in $\omega^{h}$ is similar to Figure 2, except that the threshold of $\varepsilon$ is now given by $\bar{\varepsilon}$ instead of $(1+\alpha) / \alpha$. Lemma 2 shows that the decrease in employment also reduces economic growth in the long run. Together with the decrease in $N_{t}^{h} / N_{t}^{f}$, steady-state welfare in the Home country decreases, but the welfare effect in the Foreign country is ambiguous due to the opposing effects of $g$ and $N_{0}^{f}$ on $U^{f}$ in (38). We summarize these results in Proposition 3.

Proposition 3 When a wage-oriented union has more bargaining power, employment in the domestic economy decreases. This decrease in employment increases the wage rate in the domestic economy relative to the foreign economy in the short run. In the long run, the decrease in employment in the domestic economy causes innovation to be directed to the foreign economy, which

\footnotetext{
${ }^{29}$ It is useful to note that $\bar{\varepsilon}>(1+\alpha) / \alpha$ given an upper bound imposed on $\omega^{h}$ to ensure $l^{h}>0$ in $(25)$.
} 
causes a negative effect on the relative wage. The overall long-run effect of increasing a wageoriented union's bargaining power on the relative wage is negative if and only if the substitution elasticity $\varepsilon$ is greater than a threshold given by $\bar{\varepsilon}$. Finally, the effects on the steady-state growth rate and domestic welfare are negative.

Proof. See Appendix A.

Next we consider an employment-oriented union (i.e., $\left.\omega^{h}<1\right)$. In this case, $(25)$ shows that an increase in the union's bargaining power $\theta^{h}$ raises employment $l^{h}$ in the domestic economy. Although this increase in employment causes a negative effect on relative wage $w_{t}^{h} / w_{t}^{f}$ as shown in (31), the increase in $\theta^{h}$ nevertheless increases relative wage $w_{t}^{h} / w_{t}^{f}$ in the short run. This positive short-run effect of $\omega^{h}$ on relative wage $w_{t}^{h} / w_{t}^{f}$ is due to the increase in the share of output that goes to wage income as shown in (23). As for the long-run effect of the union's bargaining power $\theta^{h}$ on relative wage $w_{t}^{h} / w_{t}^{f}$, an increase in $\theta^{h}$ further increases relative wage under an employmentoriented union because the market-size effect (by increasing $N_{t}^{h} / N_{t}^{f}$ ) works in favor of increasing $w_{t}^{h} / w_{t}^{f}$ due to the increase in employment $l^{h}$. Lemma 2 shows that this increase in employment also stimulates economic growth in the long run. Together with the increase in $N_{t}^{h} / N_{t}^{f}$, steadystate welfare in the Home country increases. In this case, the welfare effect in the Foreign country is also positive due to the positive effect of $g$ on $U^{f}$ in (38). We summarize these results in Proposition 4. Figure 3 plots the transitional path of $w_{t}^{h} / w_{t}^{f}$ in response to a permanent increase in the bargaining power $\theta^{h}$ of an employment-oriented union at time $t$.

Proposition 4 When an employment-oriented union has more bargaining power, employment in the domestic economy increases. This increase in employment causes a negative effect on the wage rate in the domestic economy. However, the increase in the union's bargaining power also increases the share of output that goes to labor income. The overall effect on the relative wage is positive in the short run. In the long run, the increase in employment causes innovation to be directed to the domestic economy, which leads to an additional positive effect on the relative wage. Therefore, the overall long-run effect of increasing an employment-oriented union's bargaining power on the relative wage is always positive. Finally, the effects on the steady-state growth rate and welfare in both countries are positive.

Proof. See Appendix A.

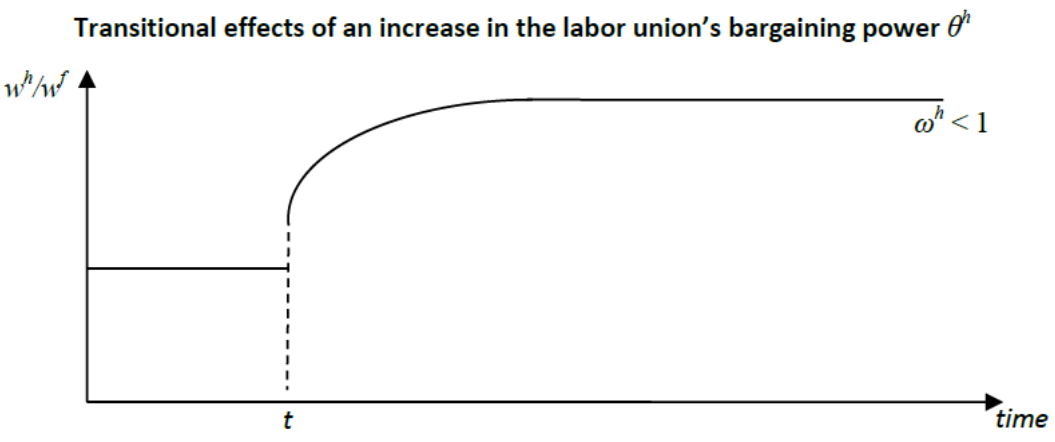

Figure 3 


\section{Quantitative analysis}

To illustrate how large an effect labor unions could have on the macroeconomy, we calibrate our stylized model to data in the US and the UK to see if it can replicate the simultaneous decrease in labor income share and unemployment from 1980 to 2007. An assumption we make is that the economy is at an initial steady state in 1980 and converges to a new steady state in 2007. Therefore, we consider the long-run trend values of labor income share and unemployment as in Figure 1. Furthermore, we assume that the decrease in labor income share is due to a decrease in workers' bargaining power $\left\{\theta^{h}, \theta^{f}\right\} .{ }^{30}$ However, it is useful to note that we do not rule out other fundamental reasons for the decrease in labor income share; for example, globalization may reduce the bargaining power of workers, which in turn decreases labor income share. Given the change in workers' bargaining power $\left\{\theta^{h}, \theta^{f}\right\}$, we compute the implied values of the unions' wage orientation $\left\{\omega^{h}, \omega^{f}\right\}$ that enable the model to deliver the observed decrease in the unemployment rates in the two countries. Given that our goal is to examine the effects of unions' bargain power, we hold other structural parameters constant when performing this numerical experiment. Finally, we also explore the quantitative implications on social welfare and wage inequality across the two countries.

The model features the following parameters $\left\{\rho, \varepsilon, \alpha, \beta, \gamma, \mu^{h}, \mu^{f}, L^{h}, L^{f}, \bar{b}^{h}, \bar{b}^{f}, \theta^{h}, \theta^{f}, \omega^{h}, \omega^{f}\right\}$. We define the US as the Home country $h$ and the UK as the Foreign country $f$. We follow Acemoglu and Akcigit (2012) to consider a standard value for the discount rate $\rho=0.05$. As for the elasticity of substitution between Home and Foreign intermediate goods, we set $\varepsilon$ to 3.5, which takes on an intermediate value of the empirical estimates summarized in McDaniel and Balistreri (2003). For the parameters in the intermediate-goods production function (8), we set the degree of labor intensity $\alpha$ to 0.5 and the intensity of intermediate goods $\beta$ to 0.2 . It is useful to recall that labor income share is given by $\alpha+\theta^{h}(1-\alpha-\beta)$ in the model. Therefore, $\alpha$ is the lower bound of labor income share, and $1-\beta$ is the upper bound. Given that labor income share has fallen to as low as 0.54 in the US in recent years, we consider labor income share bounded between 0.5 and 0.8 to be reasonable. As for the share parameter $\gamma$ in the final-goods production function (4), we calibrate it using the relative wage of the two countries, and $w_{t}^{h} / w_{t}^{f}$ is 1.45 in $1980 .{ }^{31}$ As for the R\&D productivity parameters $\left\{\mu^{h}, \mu^{f}\right\}$, it can be shown that one of these parameters can be set as a free parameter without changing the results. ${ }^{32}$ Therefore, we normalize $\mu^{f}$ to one and calibrate $\mu^{h}$ using the long-run average growth rate in the two economies for which $g$ is about $2 \%$. We normalize $L^{f}$ to one and calibrate $L^{h}$ by matching the relative size of labor force in the

\footnotetext{
${ }^{30}$ For example, Kristal (2013) uses industry-level data to show that the decrease in labor income share in the US since the early 1980's is due to the decrease in unionization and workers' bargaining power; see also Kristal (2010) and Judzik and Sala (2013) for evidence based on country-level data from a sample of countries including the UK and the US.

${ }^{31}$ Data source: Penn World Table, and OECD Annual Indicators on Unit Labour Costs. From the Penn World Table, we obtain PPP-adjusted real income per worker. Then, we use OECD data on labor income share to compute real wage income per worker in the two countries.

${ }^{32}$ In Appendix C, we show that it is the ratio $\Phi \equiv\left(\mu^{f} / \mu^{h}\right)^{(1-\beta)(\varepsilon-1)}[\gamma /(1-\gamma)]^{\varepsilon}$ that affects the quantitative results. Given a value of $\Phi$, the individual values of $\left\{\mu^{h}, \mu^{f}, \gamma\right\}$ do not matter; therefore, one of these parameters can be treated as a free parameter. Furthermore, the calibrated parameter values in Table 1 imply a value of $R^{h} / R^{f}=6.08$, which is close to the relative R\&D expenditure of 5.73 between the US and the UK in 1981; data from OECD R\&D Statistics.
} 
two countries in $1980 .{ }^{33}$ To match the unemployment rates, we calibrate the values of $\left\{\bar{b}^{h}, \bar{b}^{f}\right\}$. We use the trend values of labor income share in the two countries in 1980 and 2007 to calibrate respectively the values of $\left\{\theta^{h}, \theta^{f}\right\}$ in 1980 and 2007. Then, we calibrate the values of $\left\{\omega^{h}, \omega^{f}\right\}$ so that the calibrated economies replicate the observed decrease in the unemployment rates from $8 \%$ to $5 \%$ in the US and from $10 \%$ to $5 \%$ in the UK. ${ }^{34}$ Table 1 summarizes the calibrated parameter values.

Table 1: Calibrated parameter values

\begin{tabular}{|l|l|l|l|l|l|l|l|l|l|l|l|l|l|l|}
\hline$\rho$ & $\varepsilon$ & $\alpha$ & $\beta$ & $\gamma$ & $\mu^{h}$ & $\mu^{f}$ & $L^{h}$ & $L^{f}$ & $\bar{b}^{h}$ & $\bar{b}^{f}$ & $\omega^{h}$ & $\omega^{f}$ & $\theta^{h}$ & $\theta^{f}$ \\
\hline 0.05 & 3.5 & 0.5 & 0.2 & 0.41 & 0.54 & 1.0 & 4.1 & 1.0 & 0.13 & 0.43 & 1.14 & 1.71 & $0.53 \rightarrow 0.17$ & $0.53 \rightarrow 0.43$ \\
\hline
\end{tabular}

Figure 1a shows that labor income shares in the US and the UK were about the same at 0.66 in 1980. By 2007, labor income share in the US falls to 0.55, whereas labor income share in the UK decreases only slightly to 0.63 . Our model provides the following structural interpretation of this empirical pattern: the bargaining power of workers falls by a much larger degree in the US than in the UK, as indicated in Table 1 . The calibrated value of $\theta^{h}=0.17$ being smaller than the calibrated value of $\theta^{f}=0.43$ is consistent with the casual observation that unions in the US are less powerful than those in the UK; for example, the union density of $11.6 \%$ in the US is lower than that of $27.9 \%$ in the UK in $2007 .^{35}$

Figure $1 \mathrm{~b}$ shows that unemployment rates in the two countries fall to a similar value of $5 \%$. The fact that unemployment decreases in response to a decrease in the bargaining power of workers implies that unions are wage-oriented (i.e., $\left\{\omega^{h}, \omega^{f}\right\}>1$ ). ${ }^{36}$ Furthermore, the degree of wage orientation must be larger in the UK in order for its unemployment rate to fall by a larger magnitude despite the smaller decrease in its workers' bargaining power. Table 1 shows that the degree of wage orientation $\omega^{f}$ in the UK is 1.71 , which is larger than $\omega^{h}=1.14$ in the US. Under these values of $\left\{\omega^{h}, \omega^{f}\right\}$, decreasing workers' bargaining power $\theta^{h}$ from 0.53 to 0.17 causes the unemployment rate to decrease from $8 \%$ to $5 \%$ in the US, whereas decreasing $\theta^{f}$ from 0.53 to 0.43 causes the unemployment rate to decrease from $10 \%$ to $5 \%$ in the UK.

In the rest of this section, we simulate the long-run effects of decreasing workers' bargaining power $\left\{\theta^{h}, \theta^{f}\right\}$ on relative wage in (35) and welfare in (38) while holding other parameter values constant. We consider the calibrated parameter values and changes in $\left\{\theta^{h}, \theta^{f}\right\}$ in Table 1 . The decrease in workers' bargaining power $\left\{\theta^{h}, \theta^{f}\right\}$ leads to an increase in employment $\left\{l^{h}, l^{f}\right\}$, which in turn increases the long-run growth rate from $2 \%$ to $2.16 \% .{ }^{37}$ This positive growth effect benefits

\footnotetext{
${ }^{33}$ Data source: World Development Indicators, and Federal Reserve Economic Data.

${ }^{34}$ Our model features exogenous labor-force participation in the two countries. In the data, the labor-force participation rates increase from the early 1980's to 2007 by about two and four percentage points in the US and the UK respectively. This larger increase in the labor-force participation rate in the UK should reinforce its larger decrease in the unemployment rate. However, our model takes the labor force as given and does not shed any light on whether the changes in labor-force participation are caused by labor unions. Therefore, we focus on changes in unemployment which is determined by the bargaining power of labor unions in our analysis.

${ }^{35}$ Data source: OECD Trade Union Statistics.

${ }^{36}$ In the case of employment-oriented unions, decreasing their bargaining power would lead to lower employment and higher unemployment.

${ }^{37}$ For example, Carmeci and Mauro (2003) estimate dynamic panel regressions using data on OECD countries and find that decreasing labor union density indeed has a positive effect on long-run growth.
} 
the two countries equally. However, the larger reduction in unemployment in the UK than that in the US causes innovation to be directed to the UK and gives rise to a decrease in $N^{h} / N^{f}$.

Using data on patent grants, we construct an empirical data series on $N_{t}^{h} / N_{t}^{f}$ in Figure 4 and find that $N_{t}^{h} / N_{t}^{f}$ indeed decreases to a lower value from 1980 to 2007. We construct this time series using data from the United States Patent and Trademark Office (USPTO) and European Patent Office (EPO). ${ }^{38}$ Specifically, we use the number of patents granted by the USPTO to inventors in the US and the UK from 1977 to 2007 to obtain a time series for the flow $\dot{N}_{t}^{h}{ }^{39}$ Then, we compute the accumulated stock of patents granted by the USPTO to construct a time series for the stock $N_{t}^{h}$. Similarly, we use the number of patents granted by the EPO to inventors in the US and the UK each year to obtain a time series for $\dot{N}_{t}^{f} \cdot{ }^{40}$ Then, we compute the accumulated stock of patents granted by the EPO to construct a time series for $N_{t}^{f}$.

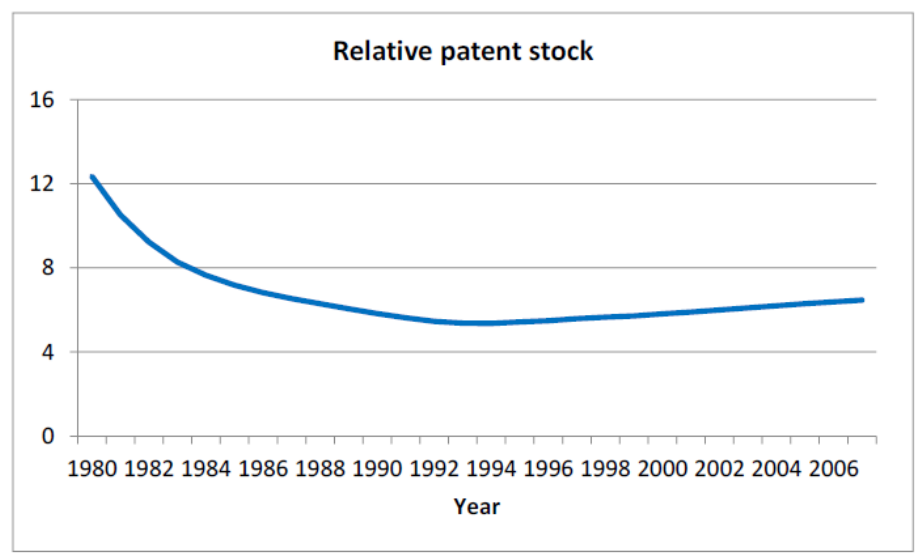

Figure 4

The decrease in $N^{h} / N^{f}$ affects the two countries differently due to changes in relative wage income. In the data, relative wage $w_{t}^{h} / w_{t}^{f}$ decreases from 1.45 in 1980 to 1.03 in 2007, ${ }^{41}$ whereas $w_{t}^{h} / w_{t}^{f}$ decreases from 1.45 to 1.26 in our simulation, which explains about half of the decrease in relative wage in the data. Finally, we also simulate the long-run welfare changes in the two countries. $^{42}$ We find that as a result of the increase in employment and growth, welfare improves in the US, and the welfare gain is equivalent to a permanent increase in consumption of $5.18 \%$. The welfare improvement in the UK is even more significant at $8.11 \%$ due to the increase in wage income relative to the US. We summarize these results in Table 2.

\footnotetext{
${ }^{38}$ Data source: OECD patent databases.

${ }^{39}$ Earlier data is not available.

${ }^{40}$ Unfortunately, we do not have data on patent grants by inventors' residence of origin at the Intellectual Property Office in the UK, so we use data from the EPO as a proxy.

${ }^{41}$ As before, we obtain PPP-adjusted real income per worker from the Penn World Table and then use OECD data on labor income share to compute real wage income per worker in the two countries. OECD also provides direct data on average annual wages, according to which relative wage of the two countries decreases from 1.30 in 1990 to 1.17 in 2007; unfortunately, earlier data is not available.

${ }^{42}$ We express welfare changes as the usual equivalent variation in annual consumption.
} 
Table 2: Simulated effects on $\left\{w_{t}^{h} / w_{t}^{f}, U^{h}, U^{f}\right\}$

\begin{tabular}{|l|l|l|}
\hline & Data & Model \\
\hline Relative wage between the US and the UK in 1980 & 1.45 & 1.45 \\
\hline Relative wage between the US and the UK in 2007 & 1.03 & 1.26 \\
\hline Welfare changes in the US & $n / a$ & $5.18 \%$ \\
\hline Welfare changes in the UK & $n / a$ & $8.11 \%$ \\
\hline
\end{tabular}

\section{Conclusion}

In this study, we have explored the macroeconomic effects of labor unions in an open-economy R\&D-based growth model. We find that the effects of labor unions on employment, innovation and economic growth are theoretically ambiguous and depend on their wage orientation. In the case of the US and the UK, wage-oriented unions seem to fit the data better by enabling the model to replicate the observed decrease in labor income share, unemployment and relative wage across countries. In this case, decreasing the bargaining power of unions stimulates employment and economic growth, as some empirical studies (discussed in the introduction) tend to find. However, when it comes to employment-oriented unions, increasing their bargaining power would raise employment and growth. These theoretical findings suggest that there is no one-size-fits-all policy when it comes to reforming existing labor-market institutions, such as labor unions. Therefore, policymakers should make an effort to understand the country-specific or even industry-specific effects of labor unions. Furthermore, to ensure analytical tractability, we have kept our model as simple as possible and neglected many realistic features of the labor market. Hence, it would be useful to structurally estimate the effects of labor unions and workers' bargaining power using a more realistic model, and we leave this interesting extension to future research.

\section{References}

[1] Acemoglu, D., 1998. Why do new technologies complement skills? Directed technical change and wage inequality. Quarterly Journal of Economics, 113, 1055-1089.

[2] Acemoglu, D., 2002. Directed technical change. Review of Economic Studies, 69, 781-809.

[3] Acemoglu, D., 2003. Patterns of skill premia. Review of Economic Studies, 70, 199-230.

[4] Acemoglu, D., Aghion, P., and Violante, G., 2001. Deunionization, technical change and inequality. Carnegie-Rochester Conference Series on Public Policy, 55, 229-264.

[5] Acemoglu, D., and Akcigit, U., 2012. Intellectual property rights policy, competition and innovation. Journal of the European Economic Association, 10, 1-42.

[6] Acemoglu, D., and Zilibotti, F., 2001. Productivity differences. Quarterly Journal of Economics, 116, 563-606. 
[7] Acs, Z., and Audretsch, D., 1988. Innovation in large and small firms: An empirical analysis. American Economic Review, 78, 678-690.

[8] Addison, J., Schnabel, C., and Wagner, J., 2001. Works councils in Germany: their effects on establishment performance. Oxford Economic Papers, 53, 659-694.

[9] Aghion, P., and Howitt, P., 1992. A model of growth through creative destruction. Econometrica, 60, 323-351.

[10] Blanchflower, D., Millward, N., and Oswald, A., 1991. Unionism and employment behavior. Economic Journal, 101, 815-834.

[11] Boone, J., 2000. Technological progress, downsizing and unemployment. Economic Journal, 110, 581-600.

[12] Bradley, D., Kim, I., and Tian, X., 2015. Do unions affect innovation?. Management Science, forthcoming.

[13] Brauninger, M., and Pannenberg, M., 2002. Unemployment and productivity growth: An empirical analysis within an augmented Solow model. Economic Modelling, 19, 105-120.

[14] Card, D., Lemieux, T., and Riddell, C., 2004. Unions and wage inequality. Journal of Labor Research, 25, 519-559.

[15] Carmeci, G., and Mauro, L., 2003. Imperfect labor market and convergence: Theory and evidence for some OECD countries. Journal of Policy Modelling, 25, 837-856.

[16] Chang, J., and Hung, H., 2015. Trade unions, unemployment, economic growth, and income inequality. Macroeconomic Dynamics, forthcoming.

[17] Chang, J., Shaw, M., and Lai, C., 2007. A "managerial" trade union and economic growth. European Economic Review, 51, 365-384.

[18] Connolly, R., Hirsch, B., and Hirschey, M., 1986. Union rent seeking, intangible capital, and market value of the firm. Review of Economics and Statistics, 68, 567-77.

[19] Dinopoulos, E., and Segerstrom, P., 2010. Intellectual property rights, multinational firms and economic growth. Journal of Development Economics, 92, 13-27.

[20] Gancia, G., and Bonfiglioli, A., 2008. North-South trade and directed technical change. Journal of International Economics, 76, 276-295.

[21] Gancia, G., and Zilibotti, F., 2005. Horizontal innovation in the theory of growth and development. In: Aghion, P., Durlauf, S., (Eds.), Handbook of Economic Growth, 1A, 111-170. North-Holland, Amsterdam.

[22] Gancia, G., and Zilibotti, F., 2009. Technological change and the wealth of nations. Annual Review of Economics, 1, 93-120. 
[23] Gordon, R., 1997. Is there a trade-off between unemployment and productivity growth?. In: Snower, D., de la Dehesa, G., (Eds.), Unemployment Policy: Government Options for the Labour Market. Cambridge University Press, Cambridge, pp. 433-463.

[24] Grossman, G., and Helpman, E., 1991. Quality ladders in the theory of growth. Review of Economic Studies, 58, 43-61.

[25] Hirsch, B., and Link, A., 1987. Labor union effects on innovative activity. Journal of Labor Research, 8, 323-332.

[26] Ji, L., Chang, J., and Huang, C., 2015. Unionization, market structure and economic growth. Southern Economic Journal, forthcoming.

[27] Judzik, D., and Sala, H., 2013. Productivity, deunionization and trade: Wage effects and labour share implications. International Labour Review, 152, 205-236.

[28] Kristal, T., 2010. Good times, bad times: Postwar labor's share of national income in capitalist democracies. American Sociological Review, 75, 729-763.

[29] Kristal, T., 2013. The capitalist machine: Computerization, workers' power, and the decline in labor's share within U.S. industries. American Sociological Review, 78, 361-389.

[30] Krol, R., and Svorny, S., 2007. Unions and employment growth: Evidence from state economic recoveries. Journal of Labor Research, 28, 525-535.

[31] McDaniel, C., and Balistreri, E., 2003. A review of Armington trade substitution elasticities. International Economics, 94, 301-313.

[32] Montgomery, E., 1989. Employment and unemployment effects of unions. Journal of Labor Economics, 7, 170-190.

[33] Nickell, S., and Layard, R., 1999. Labor market institutions and economic performance. In: Ashenfelter and Card (eds). Handbook of Labor Economics, 3C. Elsevier, Amsterdam, pp. 3029-3084.

[34] Oswald, A., 1985. The economic theory of trade unions: An introductory survey. Scandinavian Journal of Economics, 87, 160-193.

[35] Palokangas, T., 1996. Endogenous growth and collective bargaining. Journal of Economic Dynamics and Control, 20, 925-944.

[36] Palokangas, T., 2000. Labour Unions, Public Policy and Economic Growth. Cambridge: Cambridge University Press.

[37] Palokangas, T., 2004. Union-firm bargaining, productivity improvement and endogenous growth. Labour, 18, 191-205.

[38] Palokangas, T., 2005. International labor union policy and growth with creative destruction. Review of International Economics, 13, 90-105. 
[39] Pemberton, J., 1988. A "managerial" model of the trade union. Economic Journal, 98, 755771.

[40] Peretto, P., 2011. Market power, growth, and unemployment. In: de La Grandville, O., (Eds.), Economic Growth and Development (Frontiers of Economics and Globalization, Volume 11). Emerald Group Publishing, Bingley, pp. 493-525.

[41] Rivera-Batiz, L., and Romer, P., 1991. Economic integration and endogenous growth. Quarterly Journal of Economics, 106, 531-555.

[42] Romer, P., 1990. Endogenous technological change. Journal of Political Economy, 98, S71S102.

[43] Schnabel, C., and Wagner, J., 1994. Industrial relations and trade union effects on innovation in Germany. Labour, 8, 489-504.

[44] Segerstrom, P., Anant, T.C.A. and Dinopoulos, E., 1990. A Schumpeterian model of the product life cycle. American Economic Review, 80, 1077-91. 


\section{Appendix A}

Proof of Proposition 1. If $N_{t}^{h} / N_{t}^{f}$ is smaller than its unique steady-state value in (34) (i.e., $\left.N_{t}^{h} / N_{t}^{f}<\left(\mu^{h} / \mu^{f}\right)^{-(\beta+(1-\beta) \varepsilon)}[\gamma /(1-\gamma)]^{\varepsilon}\left(l^{h} / l^{f}\right)^{\alpha(\varepsilon-1)} \equiv \eta\right)$, then $\pi_{t}^{h} / \pi^{f}>\mu^{h} / \mu^{f}$ must hold, and hence, $v_{t}^{h}=\mu^{h}$ and $v_{t}^{f}=\mu^{f}$ cannot hold at once, noting (17) and (29). In fact, one can show that so long as $N_{t}^{h} / N_{t}^{f}<\eta, \pi_{t}^{h} / r_{t}=v_{t}^{h}=\mu^{h}$ and $v_{t}^{f}<\mu^{f}$, implying $\dot{N}_{t}^{h}>0$ and $\dot{N}_{t}^{f}=0$. Following Acemoglu (1998) and Acemoglu and Zilibotti (2001), we have demonstrated that only one type of innovation takes place off the steady state. Furthermore, the economy converges to the steady state and arrives there in finite time. In the steady state, $N_{t}^{h} / N_{t}^{f}$ is constant over time implying that $N_{t}^{h}$ and $N_{t}^{f}$ grow at the same rate. An analogous argument can be applied to the case of $N_{t}^{h} / N_{t}^{f}>\eta$.

Proof of Lemma 2. By (32) and $v^{h}=\mu^{h}$, the interest rate is given by

$$
r=\frac{\pi^{h}}{\mu^{h}}=\left(\frac{1-\beta}{\beta}\right) \frac{\left[\beta^{2} P^{h}\left(l^{h}\right)^{\alpha}\right]^{1 /(1-\beta)}}{\mu^{h}} .
$$

Using (A1), the Euler equation (3) becomes

$$
\frac{\dot{c}_{t}^{h}}{c_{t}^{h}}=\left(\frac{1-\beta}{\beta}\right) \frac{\left[\beta^{2} P^{h}\left(l^{h}\right)^{\alpha}\right]^{1 /(1-\beta)}}{\mu^{h}}-\rho \equiv g .
$$

(5) can be rewritten as

$$
P^{h}=\left[\gamma^{\varepsilon}+(1-\gamma)^{\varepsilon}\left(P^{h} / P^{f}\right)^{\varepsilon-1}\right]^{\frac{1}{\varepsilon-1}} .
$$

Substituting (34) into (29) leads to $P^{h} / P^{f}=\left(\mu^{h} / \mu^{f}\right)^{(1-\beta)}\left(l^{h} / l^{f}\right)^{-\alpha}$. Applying this to (A3) and substituting the resulting expression into (A2), we can obtain (36).

Proof of Lemma 3. Under the assumption of home bias in asset holding, one can rewrite (2) as

$$
v_{t}^{h} \dot{N}_{t}^{h}=r_{t} v_{t}^{h} N_{t}^{h}+\Pi_{t}^{h}+w_{t}^{h} l_{t}^{h}-c_{t}^{h},
$$

where $v_{t}^{h}=\mu^{h}$ and hence $\dot{v}_{t}^{h}=0$. On the balanced growth path, we can solve (A4) for $c_{t}^{h}$ :

$$
c_{t}^{h}=\pi_{t}^{h} N_{t}^{h}+\Pi_{t}^{h}+w_{t}^{h} l_{t}^{h}-\mu^{h} g N_{t}^{h},
$$

using $r_{t} v_{t}^{h}=\pi_{t}^{h}$ and $\dot{N}_{t}^{h}=g N_{t}^{h}$. Using (17), we obtain

$$
\pi_{t}^{h} N_{t}^{h}=\beta^{(1+\beta) /(1-\beta)}(1-\beta)\left[\left(l^{h}\right)^{\alpha} P^{h}\right]^{\frac{1}{1-\beta}} N_{t}^{h} .
$$

Here it holds that

$$
\begin{aligned}
\left(l^{h}\right)^{\alpha} P^{h} & =\left(\mu^{h}\right)^{1-\beta}\left[\gamma^{\varepsilon}\left(\mu^{h}\right)^{-(1-\beta)(\varepsilon-1)}\left(l^{h}\right)^{\alpha(\varepsilon-1)}+(1-\gamma)^{\varepsilon}\left(\mu^{f}\right)^{-(1-\beta)(\varepsilon-1)}\left(l^{f}\right)^{\alpha(\varepsilon-1)}\right]^{\frac{1}{\varepsilon-1}} \\
& =\left[\frac{\mu^{h}(g+\rho)}{\beta^{(1+\beta) /(1-\beta)}(1-\beta)}\right]^{1-\beta},
\end{aligned}
$$


where the first equality comes from (A3) with $P^{h} / P^{f}=\left(\mu^{h} / \mu^{f}\right)^{(1-\beta)}\left(l^{h} / l^{f}\right)^{-\alpha}$ and the second equality comes from (36). Using (23) and (24), we obtain

$$
\Pi_{t}^{h}+w_{t}^{h} l_{t}^{h}=(1-\beta) P_{t}^{h} X_{t}^{h}=\beta^{2 \beta /(1-\beta)}(1-\beta)\left[\left(l^{h}\right)^{\alpha} P^{h}\right]^{1 /(1-\beta)} N_{t}^{h},
$$

where we have used (28) for the second equality. Substituting (A6)-(A8) into (A5) yields

$$
c_{t}^{h}=\mu^{h}\left[\frac{(1+\beta) \rho+g}{\beta}\right] N_{t}^{h} .
$$

Substituting (A9) into (38) yields (39). Finally, $c_{t}^{f}$ can be derived analogously.

Proof of Proposition 2. It is shown in (25) that an increase in $\omega^{h}$ causes a decrease in employment $l^{h}$, which increases $w_{t}^{h} / w_{t}^{f}$ in the short run (i.e., taking $N_{t}^{h} / N_{t}^{f}$ as given) through (31). In the long run, the decrease in $l^{h}$ reduces $N_{t}^{h} / N_{t}^{f}$ (i.e., innovation to be directed towards the Foreign country) given $\varepsilon>1$; see (34). Finally, as shown in (35), this results in a reduction in $w_{t}^{h} / w_{t}^{f}$ if and only if $\alpha(\varepsilon-1)>1$, which is equivalent to $\varepsilon>(1+\alpha) / \alpha$. Finally, for the effect of $\omega^{h}$ on long-run growth, use Lemma 2. For the effect on domestic welfare, use Lemma 3 and note the decrease in $g$ together with $\dot{N}_{t}^{h}=0$ and $\dot{N}_{t}^{f}>0$ on the transitional path to the new steady state of $N_{t}^{h} / N_{t}^{f}$, which is lower than before.

Proof of Proposition 3. Under a wage-oriented union, we have $\omega^{h}>1$. We first address the short run by taking $N_{t}^{h} / N_{t}^{f}$ as given in (31). Using this fact and (25), we can rewrite (31) as

$$
\ln \left(w_{t}^{h} / w_{t}^{f}\right)=\ln \left[\alpha+\theta^{h}(1-\alpha-\beta)\right]-\frac{\alpha+\beta+(1-\alpha-\beta) \varepsilon}{\beta+(1-\beta) \varepsilon} \ln \left[\alpha+\left(1-\omega^{h}\right) \theta^{h}(1-\alpha-\beta)\right],
$$

where we have omitted some exogenous terms for simplicity. Differentiating (A10) yields

$$
\frac{\partial \ln \left(w_{t}^{h} / w_{t}^{f}\right)}{\partial \theta^{h}}=\frac{1-\alpha-\beta}{\alpha+\theta^{h}(1-\alpha-\beta)}+\frac{\alpha+\beta+(1-\alpha-\beta) \varepsilon}{\beta+(1-\beta) \varepsilon} \frac{\left(\omega^{h}-1\right)(1-\alpha-\beta)}{\alpha+\left(1-\omega^{h}\right) \theta^{h}(1-\alpha-\beta)},
$$

which is positive given $\omega^{h}>1$. In the rest of this proof, we address the long run by considering (35). In an analogous manner, we can derive from (35)

$$
\ln \left(w_{t}^{h} / w_{t}^{f}\right)=\ln \left[\alpha+\theta^{h}(1-\alpha-\beta)\right]+[\alpha(\varepsilon-1)-1] \ln \left[\alpha+\left(1-\omega^{h}\right) \theta^{h}(1-\alpha-\beta)\right],
$$

where some exogenous terms are omitted again for simplicity. Differentiating (A12) yields

$$
\frac{\partial \ln \left(w_{t}^{h} / w_{t}^{f}\right)}{\partial \theta^{h}}=\frac{1-\alpha-\beta}{\alpha+\theta^{h}(1-\alpha-\beta)}-[\alpha(\varepsilon-1)-1] \frac{\left(\omega^{h}-1\right)(1-\alpha-\beta)}{\alpha+\left(1-\omega^{h}\right) \theta^{h}(1-\alpha-\beta)} .
$$

From (A13), it can be shown that $\partial \ln \left(w_{t}^{h} / w_{t}^{f}\right) / \partial \theta^{h}<0$ if and only if $\varepsilon>\bar{\varepsilon}$. Finally, for the effect of $\theta^{h}$ on long-run growth, use Lemma 2. For the effect on domestic welfare, use Lemma 3 as in the proof for Proposition 2.

Proof of Proposition 4. Under an employment-oriented union, we have $\omega^{h}<1$. First, we consider the short-run effect by examining (A10) and (A11). In (A11), $\partial \ln \left(w_{t}^{h} / w_{t}^{f}\right) / \partial \theta^{h}$ is monotonically increasing in $\omega^{h}$ and takes a strictly positive value at $\omega^{h}=0$. Therefore, $\partial \ln \left(w_{t}^{h} / w_{t}^{f}\right) / \partial \theta^{h}$ is 
always positive for any $\omega^{h}>0$. Then, we examine the long-run effect using (A13). If $\alpha(\varepsilon-1)>1$, then $\partial \ln \left(w_{t}^{h} / w_{t}^{f}\right) / \partial \theta^{h}>0$ must hold because $\omega^{h}<1$. If $\alpha(\varepsilon-1)<1$, then $\partial \ln \left(w_{t}^{h} / w_{t}^{f}\right) / \partial \theta^{h}$ in (A13) is monotonically increasing in $\omega^{h}$ and takes a strictly positive value at $\omega^{h}=0$. Therefore, $\partial \ln \left(w_{t}^{h} / w_{t}^{f}\right) / \partial \theta^{h}$ is always positive for any $\omega^{h} \in(0,1)$. Finally, for the effect of $\theta^{h}$ on long-run growth, use Lemma 2. For the effects on domestic and foreign welfare, use Lemma 3 and note the increase in $g$ together with $\dot{N}_{t}^{h}>0$ and $\dot{N}_{t}^{f}=0$ on the transitional path to the new steady state of $N_{t}^{h} / N_{t}^{f}$, which is higher than before. 


\section{Appendix B: Balance of payments}

Suppose final goods are produced in country $f$. Let's denote $\tilde{s} \in[0,1]$ as the share of monopolistic intermediate-good firms owned by country $h, s^{h} \in[0,1]$ as the share of Home inventions created by country $h$, and $s^{f} \in[0,1]$ as the share of Foreign inventions created by country $f .{ }^{43}$ Also, let's allow for cross-country bond holding by denoting $D_{t}^{h}$ as a foreign debt of country $h$. In other words, country $f$ 's foreign asset (in terms of country $h$ 's bond) is equal to $-D_{t}^{h}$. Here, without any loss of generality, we assume that the Home country is a borrower country. Then, the following lemma holds.

Lemma 4 The current account $C A_{t}$ for country $h$ is given by

$$
C A_{t}=P_{t}^{h} X_{t}^{h}-\left(\pi_{t}^{h} N_{t}^{h}+\Pi_{t}^{h}+w_{t}^{h} l_{t}^{h}+x_{t}^{h} N_{t}^{h}+\dot{D}_{t}^{h}\right) .
$$

Proof. Under the above assumptions, country $h$ exports $X_{t}^{h}$ units of intermediate goods to country $f$, whereas country $f$ exports $c_{t}^{h}+x_{t}^{h} N_{t}^{h}+\left[s^{h} \mu^{h} \dot{N}_{t}^{h}+\left(1-s^{f}\right) \mu^{f} \dot{N}_{t}^{f}\right]$ units of final goods to country $h$. Therefore, the net export of the value of goods from country $h$ is equal to

$$
P_{t}^{h} X_{t}^{h}-c_{t}^{h}-x_{t}^{h} N_{t}^{h}-s^{h} \mu^{h} \dot{N}_{t}^{h}-\left(1-s^{f}\right) \mu^{f} \dot{N}_{t}^{f} .
$$

Country $h$ also exports the value $\left(1-s^{f}\right) \pi_{t}^{f} N_{t}^{f}+\tilde{s} \Pi_{t}^{f}$ of capital services to country $f$, whereas country $f$ exports the value $\left(1-s^{h}\right) \pi_{t}^{h} N_{t}^{h}+(1-\tilde{s}) \Pi_{t}^{h}+r_{t} D_{t}^{h}$ of capital services to country $h$. Therefore, the net export of capital services from country $h$ is equal to

$$
\left(1-s^{f}\right) \pi_{t}^{f} N_{t}^{f}+\tilde{s} \Pi_{t}^{f}-\left(1-s^{h}\right) \pi_{t}^{h} N_{t}^{h}-(1-\tilde{s}) \Pi_{t}^{h}-r_{t} D_{t}^{h} .
$$

Consumption $c_{t}^{h}$ in country $h$ can be derived from the asset-accumulation equation as ${ }^{44}$

$$
c_{t}^{h}=s^{h} \pi_{t}^{h} N_{t}^{h}+\left(1-s^{f}\right) \pi_{t}^{f} N_{t}^{f}-r_{t} D_{t}^{h}+\tilde{s}\left(\Pi_{t}^{h}+\Pi_{t}^{f}\right)+w_{t}^{h} l_{t}^{h}-s^{h} \mu^{h} \dot{N}_{t}^{h}-\left(1-s^{f}\right) \mu^{f} \dot{N}_{t}^{f}+\dot{D}_{t}^{h} .
$$

By summing up (B2a) and (B2b) with (B3), the current account becomes (B1).

Given Lemma 4, we now show that the balance of payment holds. To do so, we derive each term in the right-hand side of (B1). From (28), we have

$$
P_{t}^{h} X_{t}^{h}=\beta^{\frac{2 \beta}{1-\beta}}\left[\left(l^{h}\right)^{\alpha} P_{t}^{h}\right]^{\frac{1}{1-\beta}} N_{t}^{h} .
$$

Then, by using (17), we have

$$
\pi_{t}^{h} N_{t}^{h}=\beta^{\frac{1+\beta}{1-\beta}}(1-\beta)\left[\left(l_{t}^{h}\right)^{\alpha} P_{t}^{h}\right]^{\frac{1}{1-\beta}} N_{t}^{h} .
$$

${ }^{43}$ The setup nests the assumption in Lemma 3 as a special case with $s^{h}=s^{f}=1, \tilde{s}=\Pi_{t}^{h} /\left(\Pi_{t}^{h}+\Pi_{t}^{f}\right)$ and $D_{t}^{h}=0$.

${ }^{44}$ Using the definitions of $\tilde{s}, s^{h}$, and $s^{f}$, we can re-express (2) as

$$
\left[s^{h} v_{t}^{h} N_{t}^{h}+\left(1-s^{f}\right) v_{t}^{f} N_{t}^{f}\right]-\dot{D}_{t}^{h}=r_{t}\left[s^{h} v_{t}^{h} N_{t}^{h}+\left(1-s^{f}\right) v_{t}^{f} N_{t}^{f}-D_{t}^{h}\right]+\tilde{s}\left(\Pi_{t}^{h}+\Pi_{t}^{f}\right)+w_{t}^{h} h_{t}^{h}-c_{t}^{h} .
$$

Using the equilibrium conditions $r_{t} v_{t}^{z}=\pi_{t}^{z}$ and $v_{t}^{z}=\mu^{z}$ for $z=h, f$, we obtain (B3). 
With (B4a), (24) becomes

$$
\Pi_{t}^{h}=\left(1-\theta^{h}\right)(1-\alpha-\beta) \beta^{\frac{2 \beta}{1-\beta}}\left[\left(l^{h}\right)^{\alpha} P_{t}^{h}\right]^{\frac{1}{1-\beta}} N_{t}^{h},
$$

whereas (23) becomes

$$
w_{t}^{h} l_{t}^{h}=\left[\alpha+\theta^{h}(1-\alpha-\beta)\right] \beta^{\frac{2 \beta}{1-\beta}}\left[\left(l^{h}\right)^{\alpha} P_{t}^{h}\right]^{\frac{1}{1-\beta}} N_{t}^{h} .
$$

Recall that (16) is given by

$$
x_{t}^{h} N_{t}^{h}=\beta^{\frac{2}{1-\beta}}\left[P_{t}^{h}\left(l_{t}^{h}\right)^{\alpha}\right]^{\frac{1}{1-\beta}} N_{t}^{h} .
$$

Finally, it can be shown that substituting (B4) into (B1) yields $C A_{t}=-\dot{D}_{t}^{h}$. Given that the capital account of country $h$ is equal to $\dot{D}_{t}^{h}$, the balance of payment holds. 


\section{Appendix C (not for publication)}

In this appendix $\mathrm{C}$, we show that it is the ratio $\Phi \equiv\left(\mu^{f} / \mu^{h}\right)^{(1-\beta)(\varepsilon-1)}[\gamma /(1-\gamma)]^{\varepsilon}$ that affects the quantitative results and that given a value of $\Phi$, the individual values of $\left\{\mu^{h}, \mu^{f}, \gamma\right\}$ do not matter. Therefore, one of these parameters can be treated as a free parameter. First of all, note from (25) and (26) that the equilibrium values of $\left\{l^{h}, l^{f}\right\}$ are independent of $\left\{\mu^{h}, \mu^{f}, \gamma\right\}$.

From (35), we see that given assigned values for the relative wage $w^{h} / w^{f}$, relative employment $l^{h} / l^{f}$, labor income shares $\left\{\alpha+\theta^{h}(1-\alpha-\beta), \alpha+\theta^{h}(1-\alpha-\beta)\right\}$ and the substitution elasticity $\varepsilon$, the equation pins down a unique value of $\Phi$, which is defined as

$$
\Phi \equiv\left(\frac{\mu^{f}}{\mu^{h}}\right)^{(1-\beta)(\varepsilon-1)}\left(\frac{\gamma}{1-\gamma}\right)^{\varepsilon}=\frac{w_{t}^{h}}{w_{t}^{f}}\left(\frac{l^{f}}{l^{h}}\right)^{\alpha(\varepsilon-1)-1} \frac{\alpha+\theta^{f}(1-\alpha-\beta)}{\alpha+\theta^{h}(1-\alpha-\beta)} .
$$

Then, we can reexpress $(36)$ as

$$
g=(1-\beta) \beta^{(1+\beta) /(1-\beta)}\left\{\frac{(1-\gamma)^{\varepsilon}}{\left(\mu^{f}\right)^{(1-\beta)(\varepsilon-1)}}\left[\Phi\left(l^{h}\right)^{\alpha(\varepsilon-1)}+\left(l^{f}\right)^{\alpha(\varepsilon-1)}\right]\right\}^{\frac{1}{(1-\beta)(\varepsilon-1)}}-\rho .
$$

Therefore, given the values of $\left\{\beta, \alpha, \varepsilon, \rho, l^{h}, l^{f}, g\right\}$ and $\Phi,(\mathrm{C} 2)$ pins down a value of $(1-\gamma)^{\varepsilon} /\left(\mu^{f}\right)^{(1-\beta)(\varepsilon-1)}$. Suppose we choose a value of $\mu^{f}$. Then, (C1) and (C2) determine the values of $\left\{\mu^{h}, \gamma\right\}$.

Manipulating (34), we obtain

$$
\frac{\mu^{h} N_{t}^{h}}{\mu^{f} N_{t}^{f}}=\Phi\left(\frac{l^{h}}{l^{f}}\right)^{\alpha(\varepsilon-1)}
$$

Therefore, given the values of $\left\{\alpha, \varepsilon, l^{h}, l^{f}\right\}$ and $\Phi$, we have pined down a unique value of $\left(\mu^{h} N_{t}^{h}\right) /\left(\mu^{f} N_{t}^{f}\right)$ in (C3). Although the choice of $\mu^{f}$ affects the value of $N_{t}^{h} / N_{t}^{f}$, it does not affect the change in $\ln \left(N_{t}^{h} / N_{t}^{f}\right)$ when $\ln \left(l^{h} / l^{f}\right)$ changes as shown in (34). Similarly, one can use (C2) to show that given the values of $\Phi$ and $(1-\gamma)^{\varepsilon} /\left(\mu^{f}\right)^{(1-\beta)(\varepsilon-1)}$, the choice of $\mu^{f}$ neither affects the value of $g$ nor its change with respect to changes in $\left\{l^{h}, l^{f}\right\}$. Finally, from (38), we see that it is the changes in $\ln \left(N_{t}^{h} / N_{t}^{f}\right)$ and $g$ that affect the change in $U^{j}$; in other words, although the choice of $\mu^{f}$ affects the level of $U^{j}$, it does not affect the change in $U^{j}$. 